\title{
Intradural Extramedullary Tuberculoma of the Thoracic Spine: Paradoxical Response to Antituberculous Therapy
}

\author{
Hirokatsu Takahashi ${ }^{1}$, Shoichi Ito ${ }^{1}$, Shigeyuki Kojima ${ }^{2}$, Takaaki Tanno ${ }^{3}$ \\ and Takamichi Hattori ${ }^{1}$
}

\begin{abstract}
Intradural extramedullary tuberculoma of the spinal cord (IETSC) is a rare complication of tuberculosis, which can occur as a paradoxical response to antituberculous therapy. A 46-year-old woman with tuberculosis meningitis developed an acute sensory disturbance and paraplegia eight weeks after the antituberculous treatment was started. MRI revealed a cystic lesion at the Th 2 and 3 vertebrae levels, and continuous dural thickening. Laminectomy was performed; soft granulomas were unexpectedly observed inside the dura matter. After the operation, the patient experienced progressive improvement in motor strength. IETSC should be known as rare but possible complication of tuberculous meningitis.
\end{abstract}

Key words: MRI, intradural extramedullary tuberculoma, tuberculosis, adenosine deaminase (ADA), paradoxical response

(Inter Med 47: 797-798, 2008)

(DOI: 10.2169/internalmedicine.47.0839)

\section{Introduction}

Tuberculosis remains an important issue due to globalization and the HIV epidemic. Intradural extramedullary tuberculoma of the spinal cord (IETSC) is a rare complication of tuberculosis, which can occur as a paradoxical response to antituberculous therapy (1-3). Here, we report a case of IETSC.

\section{Case Report}

A 46-year-old Japanese-Brazilian woman was admitted to a community hospital with a 2 -week history of progressive headache, fever, and vomiting. On examination, she presented with neck stiffness. Lumbar cerebrospinal fluid (CSF) analysis showed pleocytosis $\left(226\right.$ cells $\left./ \mathrm{mm}^{3}\right)$. She was first diagnosed with bacterial meningitis, and an antibiotic regimen was started. She was moved to our hospital 3 days after admission. Initially, she did not present with paresis in her extremities. Laboratory examinations revealed a mildly elevated white blood cell count $(8,100 / \mu \mathrm{l})$ and C-reactive protein $(0.3 \mathrm{mg} / \mathrm{dl})$. HIV testing was negative. The CSF analysis revealed pleocytosis $\left(434\right.$ cells $\left./ \mathrm{mm}^{3}\right)$, increased total protein $(372 \mathrm{mg} / \mathrm{dl})$, and decreased glucose $(19 \mathrm{mg} / \mathrm{dl})$. Tubercle bacillus (TB) was not detected in the CSF, although adenosine deaminase (ADA) was elevated (14.8 IU/l) in the CSF. Computed tomography of her chest revealed miliary tuberculosis. Tuberculosis meningitis and miliary tuberculosis of the lung were suspected, and antituberculous (anti-TB) treatment with rifampicin, isoniazid, ethambutol, and pyrazinamide was started. Four days after admission to our hospital, she presented with hydrocephalus, and ventricular drainage was performed. Anti-TB treatment and ventricular drainage improved her general condition. Eight weeks after the anti-TB treatment was started, she developed an acute sensory disturbance and paraplegia with bladder and bowel involvement. Neurologic examination revealed severe muscular weakness and hyporeflexia of the bilateral lowerextremities. Extensor plantar responses were elicited bilaterally. Sensations to pin, vibration, and position were bilaterally diminished below the Th4 level of dermatome. Cervicothoracic spinal MRI revealed a cystic lesion with a well enhanced septum and rim at the Th 2 and 3 vertebrae levels,

${ }^{1}$ Department of Neurology, Graduate School of Medicine, Chiba University, Chiba, ${ }^{2}$ Department of Neurology, Matsudo City Hospital, Matsudo and ${ }^{3}$ Department of Orthopedics, Matsudo City Hospital, Matsudo

Received for publication December 18, 2007; Accepted for publication January 14, 2008

Correspondence to Dr. Hirokatsu Takahashi, takahashi.h@graduate.chiba-u.jp 

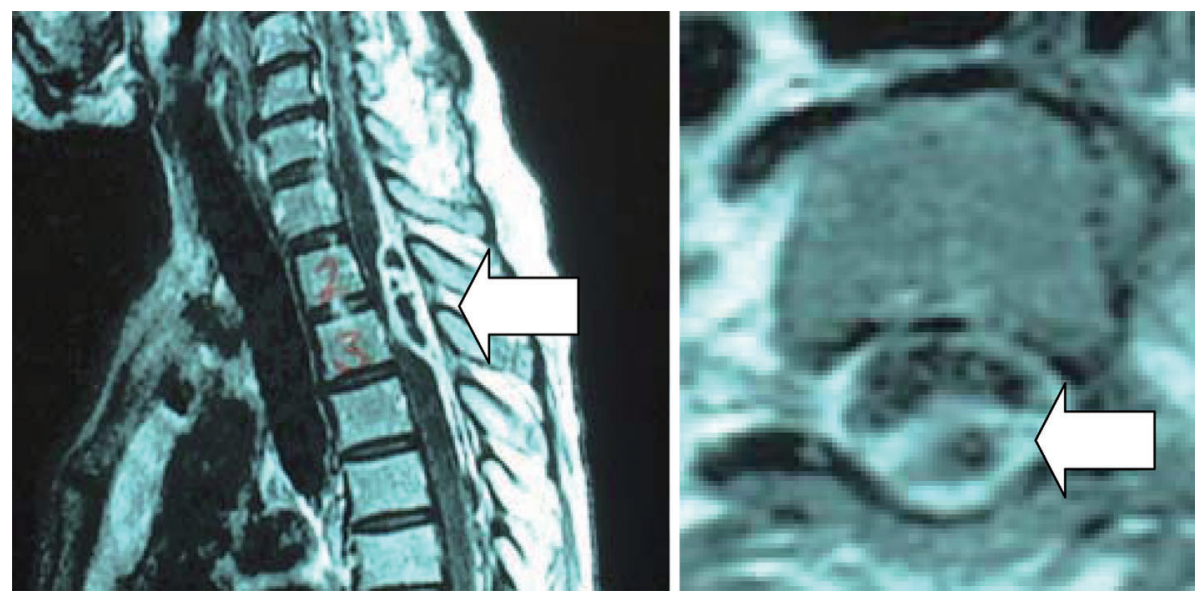

Figure 1. Preoperative thoracic T2-weighted MR images. The spinal cord is compressed by the intradural extramedullary low intensity lesions at the Th2, 3 vertebrae levels (arrows).

and continuous dural thickening(Fig. 1). High-dose intravenous methylprednisolone (1 $\mathrm{g}$ /day for 3 days) led to slight, but not satisfactory, improvement of muscle power. Laminectomy at the Th 2, 3 vertebrae levels was performed; an unexpected soft granuloma was observed in the dura mater (Fig. 2). These intradural granulomas contained white pus and TB was strongly positive in the pus. The granulomas were gently removed from the dura. After the operation, the patient experienced progressive improvement in motor strength, but she continued to have a deep sensation disturbance.

\section{Discussion}

IETSC is a rare complication of tuberculosis and can occur as paradoxical response to antituberculous chemotherapy even up to 1 year of chemotherapy (4). The pathophysiology of the paradoxical response is thought to be a result of an immunological reaction. After chemotherapy controls active $\mathrm{TB}$, host-immunosuppression due to TB resolves, and then

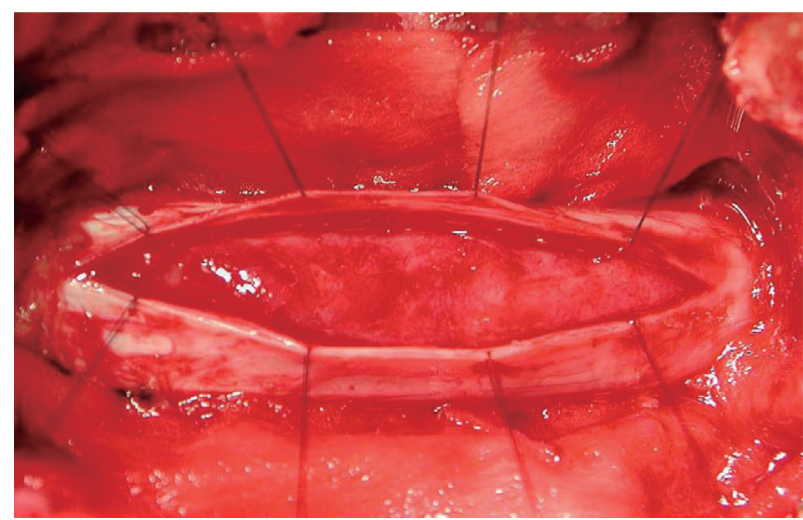

Figure 2. Intraoperative photograph showing intradural extramedullary granulomas. These granulomas contained white pus which was strongly positive for tubercle bacillus.

hypersensitivity to the protein derivatives of mycobacteria causes a paradoxical immune response $(4,5)$. IETSC as a paradoxical response should be known as rare but possible complication of tuberculous meningitis.

\section{References}

1. Luo L, Pino J. An intradural extramedullary tuberculoma of the spinal cord in a non-HIV-infected patient: case report and review of the literature. Lung 184: 187-193, 2006.

2. Skendros P, Kamaria F, Kontopoulos V, Tsitouridis I, Sidiropoulos L. Intradural, extramedullary tuberculoma of the spinal cord as a complication of tuberculous meningitis. Infection 31: 115-117, 2003.

3. Roca B. Intradural extramedullary tuberculoma of the spinal cord: a review of reported cases. J Infect 50: 425-431, 2005.

4. Kumar R, Prakash M, Jha S. Paradoxical response to chemotherapy in neurotuberculosis. Pediatr Neurosurg 42: 214-222, 2006.

5. Muthukumar N, Surreshkumar V, Ramesh VG. En plaque intradural extramedullary spinal tuberculoma and concurrent intracranial tuberculomas: paradoxical response to antituberculous therapy. J Neurosurg Spine 6: 169-173, 2007.

(C) 2008 The Japanese Society of Internal Medicine

http://www.naika.or.jp/imindex.html 